Note

\title{
Acidic resin-catalysed conversion of fructose into furan derivatives in low boiling point solvents
}

\author{
Hong Zhu ${ }^{\mathrm{a}, \mathrm{b}, \dagger}$, Quan Cao ${ }^{\mathrm{a}, \dagger}$, Chunhu Li ${ }^{\mathrm{b}}$, Xindong Mu ${ }^{\mathrm{a}, *}$ \\ a Key Laboratory of Biofuels, Qingdao Institute of Bioenergy and Bioprocess Technology, Chinese Academy of Sciences, Qingdao 266101, Shandong, China \\ ${ }^{\mathrm{b}}$ College of Chemistry and Chemical Engineering, Ocean University of China, Qingdao 266101, Shandong, China
}

\section{A R T I C L E I N F O}

\section{Article history:}

Received 15 April 2011

Received in revised form 16 May 2011

Accepted 21 May 2011

Available online 30 May 2011

\section{Keywords}

Fructose

5-Hydroxymethylfurfural

5-Methoxymethylfurfural

Methyl levulinate

Amberlyst-15

\begin{abstract}
A B S T R A C T
Conversion of fructose into furan derivatives 5-hydroxymethylfurfural (HMF) and 5-methoxymethylfurfural (MMF) is performed in tetrahydrofuran (THF) and methanol-organic solvent systems, catalysed by an acidic resin Amberlyst-15. The melted fructose can be converted into HMF on the surface of the solid resin catalyst in the presence of THF as an extracting phase, which is a good solvent for HMF and other by-products. The solid resin catalyst can be reused eleven times without losing its catalytic ability, with an average HMF yield of approximately 50\%. Upon the addition of methanol, the generated HMF can further react with methanol to form MMF, and the total yield of HMF and MMF could be promoted to $65 \%$. GC-MS analysis confirms the formation of a small amount of methyl levulinate in methanolorganic solvent system.
\end{abstract}

(C) 2011 Elsevier Ltd. All rights reserved.
With the rapid diminution of fossil fuels the price of petroleum is soaring and the cost of a petroleum-based chemical industry continues to rise. Therefore, researchers are keen to find substitutes for fossil fuels. Biomass-derived carbohydrates, which are abundant, relatively inexpensive and renewable, are a promising alternative energy source and a renewable chemical feedstock. ${ }^{1-3}$ The conversion of carbohydrates into other useful products is now of great importance. Among those products, 5-hydroxymethylfurfural (HMF), which can be produced by the dehydration of fructose, is a potential intermediate used to synthesise bio-based fuels and chemicals. ${ }^{4-7}$

The dehydration of fructose into HMF can be carried out in methanol, ${ }^{8}$ water, ${ }^{9-13}$ organic solvents of high boiling point ${ }^{14-18}$ and ionic liquids. ${ }^{19-26}$ Some acidic catalysts are usually needed to assist the reaction. Liquid acids, although possessing moderate to excellent catalytic ability in fructose dehydration towards HMF in the aforementioned media, ${ }^{13,15,18,24}$ are highly corrosive and hard to separate from the reaction system, hindering their use in industrial manufacture.

Recent years witnessed frequent use of solid acids in converting fructose to $\mathrm{HMF},{ }^{11,16,27}$ for they are convenient to be handled and recycled with low corrosiveness to equipment. As with liquid acids, excellent catalytic activities have been demonstrated in several solid acid catalytic systems. For example, the solid acidic resin

\footnotetext{
* Corresponding author. Tel.: +86 5328066 2723; fax: +86 53280662724 .

E-mail addresses: caoquan@qibebt.ac.cn (Q. Cao), muxd@qibebt.ac.cn (X. Mu).

${ }^{\dagger}$ Hong Zhu and Quan Cao contribute equally to this work.
}

Amberlyst-15 was reported to be able to convert fructose into HMF with $100 \%$ yield in dimethyl sulfoxide (DMSO). ${ }^{16}$ However, the separation of HMF from DMSO requires significant energy input to evaporate DMSO. ${ }^{2}$ Moreover, the evaporation of the solvent will result in a highly concentrated HMF, which is unstable at high temperatures due to the undesired side reactions as described in Scheme $1 .^{2}$ Dumesic and co-workers pointed out in their literature that at $343 \mathrm{~K}$ and $1.3 \mathrm{mbar}$, evaporating DMSO from $10 \mathrm{wt} \% \mathrm{HMF}$ solution will lead to a $30 \%$ loss of $\mathrm{HMF}^{2}$ Although more than $80 \%$ HMF yield can be achieved in 1-butyl-3-methylimidazolium chloride $(\mathrm{BmimCl})$ catalysed by Amberlyst $-15,{ }^{27}$ the separation of HMF and the recycling of the ionic liquid are still two problems to be solved. The catalytic activities of most solid acids were found to be unsatisfactory in water with low HMF yields even at high reaction temperatures. For instance, Asghari and Yoshida used zirconium phosphate as catalyst to convert fructose into HMF at $513 \mathrm{~K}$. However, only a 50\% HMF yield was obtained. ${ }^{11}$

Solid acid-catalyzed conversion of fructose into furan derivatives, in organic solvents with low boiling point, has not been reported to date. In this paper, the catalytic activity of the solid acid Amberlyst-15 was further investigated in the conversion of fructose into 5-hydroxymethylfurfural (HMF) and 5-methoxymethylfurfural (MMF) in different low boiling point solvent. The advantages of solid catalyst together with the volatile solvents lie in not only low corrosiveness to equipment but also low energy consumption during the separation process.

When fructose was mixed with THF and Amberlyst-15 at $120^{\circ} \mathrm{C}$, it was found that the fructose was almost insoluble in 


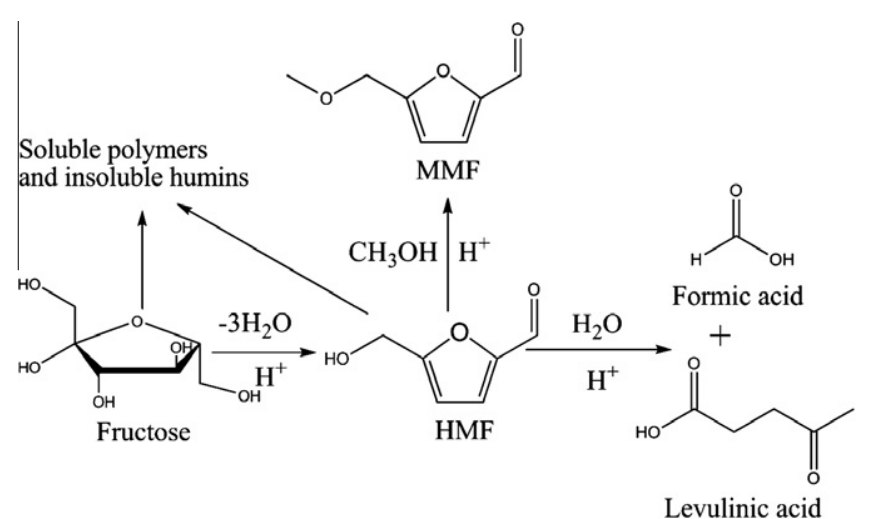

Scheme 1. Reaction pathways for the synthesis of 5-hydroxymethylfurfural and 5methoxymethylfurfural from fructose.

THF. However, at such a high temperature, the fructose melted to yield a viscous liquid, which can then make good contact with the Amberlyst-15 and the dehydration of fructose took place. In addition to HMF, all the products are soluble in THF so that the products can be extracted into the THF phase in-situ and the reaction proceeds smoothly. The THF layer could be recovered by simple decantation and then analysed using HPLC to determine the yield of HMF with the results shown in Table 1. It can be seen that as the amount of fructose decreased, both the fructose conversion and the HMF yield slightly increased, which might be ascribed to the poor thermal stability of fructose. ${ }^{28}$ The higher the fructose concentration in the reaction system, the more side reactions there are. $^{28}$

As illustrated in Table 1, entry 3, $0.29 \mathrm{~g}$ Amberlyst-15 was subsequently reused to investigate its stability towards catalyst recycling. For each run, $0.25 \mathrm{~g}$ fructose and $10 \mathrm{~mL}$ THF were added and the reaction proceeded at $120^{\circ} \mathrm{C}$ for $20 \mathrm{~min}$. After the THF layer was recovered, the solid acid Amberlyst-15 was dried in vacuum to remove the volatile component for the next cycle. 43.1-52.7\% HMF yield could be achieved in each run. After recycling for eleven times, Amberlyst-15 still retained activity and the overall average yield of HMF was $48.3 \%$. Although the HMF yield obtained in this way was much lower than that in DMSO or ionic liquids, it presented a new approach to synthesise HMF from fructose, which facilitated the separation of products with the solvent.

Methanol, a polar and inexpensive organic solvent with its boiling point of only $64.5^{\circ} \mathrm{C}$, is an excellent solvent in the preparation of HMF. Although the solubility of fructose in methanol at $25^{\circ} \mathrm{C}$ was reported to be only $85 \mathrm{~g} / \mathrm{L},{ }^{8}$ our visual observation demonstrated that $2 \mathrm{~g}$ fructose could be dissolved in $10 \mathrm{~mL}$ anhydrous methanol at $120^{\circ} \mathrm{C}$. In the presence of Amberlyst- 15 as the catalyst, conversion of fructose into HMF occurred with the results shown in Table 2 . As can be seen from the data in the table, just as the previously reported methanol- $\mathrm{H}_{2} \mathrm{SO}_{4}$ system, ${ }^{8}$ the HMF formed can further react with methanol to produce 5-methoxymethylfurfural (MMF). As a furan derivative,

Table 1

Conversion of fructose in $\mathrm{THF}^{\mathrm{a}}$

\begin{tabular}{llll}
\hline Entry & $m_{\text {Fructose }} / m_{\text {Amberlyst-15 }}$ & $Y_{\mathrm{HMF}^{\mathrm{b}}}(\%)$ & Conversion $^{\mathrm{b}}(\%)$ \\
\hline 1 & 3.47 & 35.8 & 94.5 \\
2 & 1.68 & 41.9 & 95.3 \\
3 & 0.86 & 48.0 & 98.0 \\
\hline
\end{tabular}

a Reaction conditions: $120^{\circ} \mathrm{C}$; $20 \mathrm{~min}$ reaction time; THF $10 \mathrm{~mL}$; entry 1 : Amberlyst-15 $0.30 \mathrm{~g}$; entry 2: Amberlyst-15 $0.31 \mathrm{~g}$; entry 3: Amberlyst-15 $0.29 \mathrm{~g}$.

b The HMF yield and fructose conversion were determined by HPLC.
Table 2

Conversion of fructose in methanol-THF system ${ }^{\mathrm{a}}$

\begin{tabular}{lllllll}
\hline Entry & $\begin{array}{l}V_{\text {Methanol }} / \\
V_{\mathrm{THF}}\end{array}$ & $\begin{array}{l}m_{\text {Amberlyst- }} / m_{\text {Fructose }} \\
15\end{array}$ & $\begin{array}{l}Y_{\mathrm{HMF}}{ }^{\mathrm{b}} \\
(\%)\end{array}$ & $\begin{array}{l}Y_{\mathrm{MMF}}^{\mathrm{b}} \\
(\%)\end{array}$ & $\begin{array}{l}Y_{(\mathrm{HMF}+\mathrm{MMF})} \\
(\%)\end{array}$ & $\begin{array}{l}\text { Conversion }^{\mathrm{b}} \\
(\%)\end{array}$ \\
\hline 1 & $10 / 0$ & 0.095 & 4.5 & 31.9 & 36.4 & 91.4 \\
2 & $10 / 0$ & 0.15 & 3.8 & 40.1 & 43.9 & 96.1 \\
3 & $5 / 5$ & 0.15 & 14.4 & 47.0 & 61.4 & 96.6 \\
4 & $4 / 6$ & 0.15 & 22.5 & 38.9 & 61.4 & 96.4 \\
5 & $3 / 7$ & 0.095 & 26.6 & 38.4 & 65.0 & 95.0 \\
6 & $3 / 7$ & 0.15 & 21.7 & 43.0 & 64.7 & 97.0 \\
7 & $2 / 8$ & 0.15 & 28.8 & 36.6 & 65.4 & 97.4 \\
\hline
\end{tabular}

a Reaction conditions: fructose $2 \mathrm{~g} ; 120^{\circ} \mathrm{C} ; 180 \mathrm{~min}$ reaction time; $V_{\text {methanol }}+V_{\mathrm{THF}}=10 \mathrm{~mL}$.

$\mathrm{b}$ The HMF yield and fructose conversion were determined by HPLC.

MMF itself has already been reported to be a fuel additive ${ }^{29}$ and a potential precursor to synthesise some value-added products. Apart from HMF and MMF, other by-products are all soluble in the reaction system.

Compared to the reaction data in Table 1 , the addition of methanol to THF can improve the overall yield of furan derivatives, which is probably because of the consequential etherification between HMF and methanol catalyzed by the solid acid. However, when methanol was used as the sole solvent, less than $5 \%$ HMF yield was obtained and the total yield of HMF and MMF was less than $45 \%$. When a specified volume of methanol was replaced by THF (Table 2), $2 \mathrm{~g}$ fructose is also soluble in the mixed solvents. Compared with the methanol system, the MMF yield did not change much while the HMF yield increased by over $20 \%$. When $V_{\text {Methanol }}: V_{\text {THF }}$ was $2: 8$, the total yield of HMF and MMF could reach $65.4 \%$. As $V_{\text {Methanol }}: V_{\text {THF }}$ decreased to $1: 9,2 \mathrm{~g}$ fructose was not completely soluble in the mixed solvent due to its weak polarity. In the previously reported methanol$\mathrm{H}_{2} \mathrm{SO}_{4}$ system, ${ }^{8}$ although a total yield of $\mathrm{HMF}$ and MMF could reach approximately $76 \%$ at $240{ }^{\circ} \mathrm{C}$, its fructose concentration was as low as $10 \mathrm{~g} / \mathrm{L}$ and the $\mathrm{H}_{2} \mathrm{SO}_{4}$ catalyst was highly corrosive at such a high temperature. The fructose content in this work is $200 \mathrm{~g} / \mathrm{L}$, which is considerably higher than that of methanol$\mathrm{H}_{2} \mathrm{SO}_{4}$ system and is therefore more meaningful in process economy.

To further analyse the products produced during the fructose dehydration in methanol-THF solvents, the liquid phase of entry 6 in Table 2 recovered after reaction was dried in vacuum to remove the volatile components. The residue was then extracted with $80 \mathrm{~mL}$ diethyl ether three times. The combined ether layer was subsequently analysed using GC-MS with its gas chromatogram and the corresponding mass spectrum shown in Figure S1.

It can be seen from FigureS1(a) that the diethyl ether phase consists of three main products. According to their corresponding mass spectra, they are determined to be HMF, MMF, and a small amount of methyl levulinate which is also regarded as a potential biofuel or fuel additive ${ }^{30}$ and might be the product of levulinic acid reacting with methanol. Assuming all the three components can be extracted into the diethyl ether phase, the yield of methyl levulinate by the areas of peak normalisation method was estimated to be around $4.8 \%$.

Because the HMF yield increased dramatically in the methanolTHF solvent, the reactivity of fructose was further tested in methanol-acetone, methanol-ethyl acetate or methanol-chloroform and the results displayed in Table 3 . When the $V_{\text {Methanol }}: V_{\text {(ethyl ace- }}$ tate) or $V_{\text {Methanol }}: V_{\text {chloroform }}$ was 3:7, a part of fructose was insoluble. Compared with the experimental results in Table 2, although the total yield of HMF and MMF in Table 3 was higher than that of the solely methanol system, it was still lower than that of methanol-THF system. 
Table 3

Conversion of fructose in methanol-organic solvent system ${ }^{\mathrm{a}}$

\begin{tabular}{llllll}
\hline Entry & $\begin{array}{l}V_{\text {Methanol }} / V_{\text {(organic }} \\
\text { solvent) }\end{array}$ & $\begin{array}{l}Y_{\mathrm{HMF}}{ }^{\mathrm{b}} \\
(\%)\end{array}$ & $\begin{array}{l}Y_{\mathrm{MMF}}{ }^{\mathrm{b}} \\
(\%)\end{array}$ & $\begin{array}{l}Y_{(\mathrm{HMF}+\mathrm{MMF})} \\
(\%)\end{array}$ & $\begin{array}{l}\text { Conversion }^{\mathrm{b}} \\
(\%)\end{array}$ \\
\hline 1 & $3 / 7$ & 18.0 & 35.8 & 53.8 & 95.1 \\
2 & $5 / 5$ & 12.4 & 34.4 & 46.8 & 95.0 \\
3 & $5 / 5$ & 17.0 & 37.5 & 54.5 & 96.1 \\
\hline
\end{tabular}

a Reaction conditions: fructose $2 \mathrm{~g}$; Amberlyst-15 $0.30 \mathrm{~g} ; 120^{\circ} \mathrm{C} ; 180 \mathrm{~min}$ reaction time; $V_{\text {methanol }}+V_{\text {(organic solvent) }}=10 \mathrm{~mL}$. 1: acetone; 2 : ethyl acetate; 3 : chloroform.

b The HMF yield and fructose conversion were determined by HPLC.

\section{Experimental}

\subsection{Materials and experimental procedures}

Fructose $(\geqslant 99 \%$ ) purchased from Solarbio Science \& Technology Co., Ltd was used as a standard. 5-Hydroxymethylfurfural ( $\geqslant 99 \%$ ) and 5-methoxymethylfurfural $(\geqslant 98 \%$ ) obtained from WuJiang YingChuang Chemical Reagent Co., Ltd were used as standards. Anhydrous $\mathrm{MeOH}(\geqslant 99.5 \%)$, acetone $(\geqslant 99.5 \%$ ) and chloroform $(\geqslant 99.0 \%)$ were purchased from Tianjin Guangcheng Chemical Reagent Co., Ltd. Tetrahydrofuran (chromatographic grade) was obtained from SafeNet Tianjin Science and Technology Co., Ltd. Ethyl acetate $(\geqslant 99.5 \%$ ) and anhydrous diethyl ether were supplied by Guangdong Guanghua Chemical Factory Co., Ltd. Amberlyst-15 was purchased from Sigma-Aldrich.

In a typical reaction, a certain amount of fructose, anhydrous $\mathrm{MeOH}$, tetrahydrofuran and Amberlyst-15 were charged into a $100 \mathrm{~mL}$ autoclave vessel lined with Teflon. The vessel was then heated in an oil bath preset at $120^{\circ} \mathrm{C}$ with stirring for a fixed time and then cooled down to room temperature. The liquid phase was decanted, diluted with water and then analysed using HPLC to determine the content of HMF and MMF.

\subsection{Analytical methods}

HMF and MMF were quantified using a Waters HPLC with an UV detector at $284 \mathrm{~nm}$ and a SunFire ${ }^{\mathrm{TM}} \mathrm{C}_{18}$ column $(4.8 \times 150 \mathrm{~mm})$ at $35^{\circ} \mathrm{C}$. The eluent whose flow rate was $0.6 \mathrm{~mL} / \mathrm{min}$ was a mixture of $\mathrm{MeOH}$ and water with a $\mathrm{MeOH}$ to water volumetric ratio of 1:4. The amount of HMF and MMF was calculated using the external standard.

The fructose concentration was determined using a high-performance ion-exchange chromatograph with a pulsed amperometric detector (Dionex, ICS-3000) and a CarboPac ${ }^{\mathrm{TM}}$ PA10 carbohydrate column $(4 \times 250 \mathrm{~mm})$ at $30^{\circ} \mathrm{C}$. The eluent was a $7.5 \mathrm{mM} \mathrm{NaOH}$ aqueous solution with a flow rate of $1.0 \mathrm{~mL} / \mathrm{min}$. The amount of fructose was calculated using the external standard.
GC-MS was performed using an Agilent 7890A gas chromatograph with a $5975 \mathrm{C}$ mass spectrometry detector. The temperature of the column (DB-5 ms, $50 \mathrm{~m} \times 250 \mu \mathrm{m} \times 0.25 \mu \mathrm{m}$ ) was maintained at $50{ }^{\circ} \mathrm{C}$ for $3 \mathrm{~min}$ and then raised to $300{ }^{\circ} \mathrm{C}$ with a ramp rate of $15^{\circ} \mathrm{C} / \mathrm{min}$ for $5 \mathrm{~min}$. The flow rate of Helium was $1 \mathrm{~mL} / \mathrm{min}$ with the split ratio of $20: 1$.

\section{Acknowledgements}

This work is supported by the National High Technology Research and Development Program of China (No. 2009AA05Z410), the Natural Science Foundation of China (No. 20803038, 21003146), the Key Science and Technology Program of Shandong Province (No. 2008GG20002038), and the Natural Science Foundation of Shandong Province (No. ZR2010BQ014).

\section{Supplementary data}

Supplementary data associated with this article can be found, in the online version, at doi:10.1016/j.carres.2011.05.026.

\section{References}

1. Huber, G. W.; Chheda, J. N.; Barrett, C. J.; Dumesic, J. A. Science 2005, 308, 1446 1449.

2. Román-Leshkov, Y.; Chheda, J. N.; Dumesic, J. A. Science 2006, 312, 1933-1937.

3. Román-Leshkov, Y.; Barrett, C. J.; Liu, Z. Y.; Dumesic, J. A. Nature 2007, 447 982-985.

4. Chheda, J. N.; Román-Leshkov, Y.; Dumesic, J. A. Green Chem. 2007, 9, 342-350.

5. Tong, X.; Ma, Y.; Li, Y. Appl. Catal., A 2010, 385, 1-13.

6. McNeff, V. C.; Nowlan, D. T.; McNeff, L. C.; Yan, B.; Fedie, R. L. Appl. Catal., A 2010, 384, 65-69.

7. West, R. M.; Liu, Z. Y.; Peter, M.; Dumesic, J. A. ChemSusChem 2008, 1, 417-424.

8. Bicker, M.; Kaiser, D.; Ott, L.; Vogel, H. J. Supercrit. Fluids 2005, 36, 118-126.

9. Watanabe, M.; Aizawa, Y.; Iida, T.; Nishimura, R. Appl. Catal., A 2005, 295, 150 156.

10. Asghari, F. S.; Yoshida, H. Ind. Eng. Chem. Res. 2006, 45, 2163-2173.

11. Asghari, F. S.; Yoshida, H. Carbohydr. Res. 2006, 341, 2379-2387.

12. Asghari, F. S.; Yoshida, H. Ind. Eng. Chem. Res. 2007, 46, 7703-7710.

13. Hansen, T. S.; Woodley, J. M.; Riisager, A. Carbohydr. Res. 2009, 344, 2568-2572.

14. Qi, X.; Watanabe, M.; Aida, T. M.; Smith, R. L. Ind. Eng. Chem. Res. 2008, 47, 9234-9239.

15. Binder, J. B.; Raines, R. T. J. Am. Chem. Soc. 2009, 131, 1979-1985.

16. Shimizu, K.; Uozumi, R.; Satsuma, A. Catal. Commun. 2009, 10, 1849-1853.

17. Tong, X.; Li, Y. ChemSusChem 2010, 3, 350-355.

18. Tong, X.; Ma, Y.; Li, Y. Carbohydr. Res. 2010, 345, 1698-1701.

19. Moreau, C. Finiels, A. Vanoye, L. J. Mol. Catal. A: Chem. 2006, 253, 165-169.

20. Zhao, H.; Holladay, J. E.; Brown, H.; Zhang, Z. C. Science 2007, 316, 1597-1600.

21. Yong, G.; Zhang, Y.; Ying, J. Y. Angew. Chem., Int. Ed. 2008, 47, 9345-9348.

22. Chan, J. Y. G.; Zhang, Y. ChemSusChem 2009, 2, 731-734.

23. Lima, S.; Neves, P.; Antunes, M. M. Appl. Catal., A 2009, 363, 93-99.

24. Sievers, C.; Musin, I.; Marzialetti, T. ChemSusChem 2009, 2, 665-671.

25. Qi, X.; Watanabe, M.; Aida, T. M. ChemSusChem 2009, 2, 944-946.

26. Lee, J. W.; Ha, M. G.; Yi, Y. B.; Chung, C. H. Carbohydr. Res. 2011, 346, 177-182.

27. Qi, X.; Watanabe, M.; Aida, T. M. Green Chem. 2009, 11, 1327-1331.

28. Örsi, F. J. Therm. Anal. 1973, 5, 329-335.

29. Gruter, G. J. M.; Dautzenberg, F. EP Patent 1834 950, 2007.

30. Zhang, Z.; Dong, K.; Zhao, Z. ChemSusChem 2011, 4, 112-118. 